\title{
Exploring How Teaching the Subject of Statistics Can Be Integrated into Today's Kindergartens
}

\author{
Eleni Sfyri \\ University of East London, London, UK \\ Email: esfyri@uel.uk
}

How to cite this paper: Sfyri, E. (2020) Exploring How Teaching the Subject of Statistics Can Be Integrated into Today's Kindergartens. Open Access Library Journal, 7: e6526.

https://doi.org/10.4236/oalib.1106526

Received: June 15, 2020

Accepted: August 16, 2020

Published: August 19, 2020

Copyright $\odot 2020$ by author(s) and Open Access Library Inc.

This work is licensed under the Creative Commons Attribution International License (CC BY 4.0).

http://creativecommons.org/licenses/by/4.0/

\section{(c) (i) Open Access}

\begin{abstract}
The present work was carried out within the framework of the undergraduate program of pedagogy and more specifically pre-school education of the Metropolitan College. The choice of the topic to be analyzed was out of my own interest because I always wanted to learn how each teacher sees his/her work and whether he/she considers it that he/she can do it right. In addition, in order to conduct this research, quantitative research was used to try to capture the view of forty (40) preschool teachers on the teaching of the subject of statistics in kindergartens. The tool used to conduct the research was the questionnaire used by Aggelopoulou in her research, which was based on the questions used in the TMSS- $4^{\text {th }}$ Grade Teacher Questionnaire (2011) and was applied to 40 primary school teachers. In addition, the general purpose of this research is to explore how teaching the subject of statistics can be integrated into today's kindergartens. The results will greatly help educational research so that there is more knowledge on this subject.
\end{abstract}

\section{Subject Areas}

Education

\section{Keywords}

Teaching, Pre-School Teachers, Statistics, Kindergarten, Integration

\section{Introduction}

The purpose of this research is to explore how teaching the subject of statistics can be integrated into today's kindergartens. In addition, it is important to mention that teachers' responses should be positive in terms of teaching the subject. 
In other words, the main purpose of the proposed research is that teachers should have enriched their knowledge about the views that exist regarding the teaching of the subject of statistics. In general, the above knowledge is particularly useful for enriching educational research.

In addition, the level of teachers' knowledge of statistics is not sufficient, and this often results in disagreements over whether or not to teach statistics in kindergarten. That is, the way in which each teacher teaches children in general, has the effect of leading them to learn new concepts but also to gain experiences that can be made through a game or through a puzzle that the teacher has set in his time course [1]. Regarding all teachers, they must show interest as through the effort and conduct of the research that has been studied, it has been found that the number of teachers interested in the proper education of children from preschool age is small. This is because modern man today cannot cope with grammar as more emphasis is placed on statistical content than on skills such as awareness and critical thinking [2].

There are also many motivations. Initially, children have the opportunity to benefit because through these activities they become "little researchers" and so they constantly discover new things that lead them to learn how to manage problems. Teachers, on the other hand, become more familiar with the study of statistics and thus cultivate their ability to teach new methods. In other words, kindergarten statistics should now be an integral part of children's daily lives. The research questions that arise in the following research are:

- What are the teachers' views on the introduction of teaching statistical concepts in kindergarten?

- What is the knowledge of teachers in the field of statistics?

- How teachers evaluate the ability to plan activities to teach statistical concepts?

In addition, reference is made to the literature review, to the research methodology, to the ethical issues, to the code of ethics and ethics, to the analysis of the results collected from the questionnaires and to the conclusions. Finally, it is important to note that mathematics should be taught in school classrooms, as long as teachers have the appropriate knowledge and are able to pass on new concepts and experiences to children, which are particularly useful.

\section{Theoretical Framework}

Mathematics today is one of the most important elements and for this reason they have been officially established in our country. More specifically, the Ministry of Education states that mathematics is a learning process that takes place through a construction activity where the knowledge and experience of each student becomes the precondition [3]. In addition, Koleza [4] points out that mathematical operations must be discovered through appropriate experiences that the teacher has passed on to the children.

In particular, by statistical term we mean the scientific branch of mathematics 
in the context of which we collect, group and compare data. Regarding the knowledge of mathematics, it is an essential element that contributes to both progress and the achievement of the goals of personal and professional development. For example, a part of mathematics is statistics, which has a direct and indirect sequence with the use and understanding of the functions of new technological advances that have an impact on the workplace [5]. Then the main goal of the teachers is to create knowledge in the children as well, thus expanding their skills and abilities. Additional research has shown that there is no modern data because teachers' knowledge is incomplete and this is due to their insufficient knowledge but also to the fear that statistics in kindergarten has created many obstacles [6].

According to Kontogianni [7], it has been found that statistics began as a practical activity that greatly helped solve problems. Chatzipantelis [8] states that statistics within the school functions as "a tool for use and analysis, a vehicle for understanding and constructing simple and complex school, cognitive and useful activities" [1]. In other words, teachers need to be able to apply certain goals in order to be able to pass on new knowledge to children. These are: First, they need to dispel their fears and anxieties when they are asked to teach subjects related to mathematical concepts such as statistics, by trying to see it as a new opportunity and thus achieve their goal [9]. Another reason is that they can ensure children's trust, as children as young as four have the ability to understand some basic concepts of statistics [1]. Therefore, teaching the subject of statistics can be made easier, if teachers create various games and activities in the classroom, so as to lead children to learn new concepts [10].

At the same time, the unity of statistics is a fundamental part of mathematics and for this reason the interpretation and evaluation of data has as its main goal the drawing of conclusions and decision-making, which are basic skills in modern society [11]. In other words, teaching statistics should focus mainly on the development of students' statistical thinking, which results from conducting research, understanding statistical concepts, interpreting statistical results and observing uniformities and drawing conclusions [12]. In addition, mathematics is now considered one of the most important subjects. That is, mathematical knowledge and experience is the key to success in professional and everyday life, as the technological revolution has created an environment that refers mainly to teachers but also to children who face difficulties in mathematics [5].

However, the difficulty of this subject is that on the one hand it presents its importance and on the other hand it presents the causes which are related to the performance of the students but also to the reactions of the parents and the teachers towards the mathematics. In other words, teachers should be properly informed and prepared for the current conditions that may prevail in the classroom so as not to create a feeling of fear and insecurity regarding the teaching of the subject of statistics [13]. Gal [14] argues that the teaching of the subject of statistics should be done through various active practices. For example, when a 
teacher is asked to teach a lesson, he/she must first explain to the children the data he/she uses and then continue to teach the subject so that there is a positive and causal approach so that the students have the ability to form their own views.

Based on other research that has emerged, there has been a strong interest in building statistics teaching in kindergartens. As mentioned before, 4-year-old are able to handle some basic concepts of statistics. This is because the teacher has made a lot of effort and has achieved the result he/she wanted. It is equally important to mention that children are ready to make assumptions about the part of the exercises set by the teacher and in this way they are given the opportunity to discuss the causal relationships that arise through the activities created by the teacher [15].

In addition, there are many examples that the teacher can use. One of them is the "dice". In this game children begin to acquire the ability to understand that the dice has 6 possibilities in one throw. In case the rolling dice has the number one the throw will be small, while if the number ten falls the roll will be large [1]. Based on all the above, it is found that each teacher must have the appropriate equipment and knowledge, when called to teach the subject of statistics to preschool children with the main goal of creating a first statistical base through appropriate activities that bring significant changes. Therefore, this research is based on the starting point of preschool age, in which an introduction is made to the tools and concepts used by the teacher so that his/her students become "little researchers", who have the opportunity to acquire new knowledge but also to learn how data is analyzed [16].

\section{Methodology}

This paper is part of the educational research. More specifically, educational research defines the effort made by the researcher in order to improve the operation of the system in his own way. That is, educational research helps the teacher to solve problems with practices that are applicable [17].

In addition, there are three types of methodologies. These are: quantitative, qualitative and mixed. Quantitative research was used in this work. Quantitative research is generally known as experimental, laboratory, descriptive and survey. In addition, quantitative research can be defined as a method that refers mainly to quantitative identification but also to data collection and for this reason it is a more common method in pedagogical methods. In other words, quantitative research is not always easy and therefore requires systematic planning and organization, so that data can be quantified and displayed on numbers or blueprints, which can be compared to other tables in another research [18].

\section{Research Tools}

The research tools available are: the questionnaire, the interview and the observation. In the present work the tool used is the questionnaire. In particular, the 
questionnaire is a set of written questions related to an issue that the researcher cites in a sample of individuals in order to gather the necessary research information. In this way, we collect the information we need [19]. Creating the questionnaire is easier because it is cheaper and respondents can answer freely without any restriction and so researchers are not affected by the answers of respondents [20]. Of course, the main element of the questionnaire is that individuals must answer the same questions in order to collect some data on views, attitudes and characteristics [18]. More specifically, the questionnaire used was drawn from Aggelopoulou's [21] bibliography and tested for its reliability and validity and based on the questions used in the TMSS $-4^{\text {th }}$ Grade Teacher Questionnaire 2011. More specifically, it contains eight demographic questions, three closed-ended questions, two open-ended questions and eleven five-point $\mathrm{Li}$ kert-scale teaching questions ( $1=\mathrm{I}$ completely disagree, $5=\mathrm{I}$ totally agree).

\section{Sampling}

Symptomatic sampling is the sample that has all the characteristics and in this way the researcher has the ability to find them more easily because they are immediate and available [17]. Even the specific methodology is a simple and accurate method as it describes the achievement of the representativeness of the sample [22]. However, 40 pre-school teachers, aged 20 to 40 , are asked to answer the questionnaire.

Another definition that needs to be mentioned is validity and reliability. More specifically, reliability is the way in which the tool used in research is valid. However, the validity refers to the degree to which the researcher knows that his tool is valid and reliable [23]. Therefore, validity is the basic condition for both qualitative and quantitative research and for this reason it plays an important role as it can be ensured through the careful collection of sample of the appropriate research tool and proper data management [24].

In this study, the validity and reliability of quantitative data are ensured through careful sampling by a representative population of the sample (at least 40 preschool teachers). This sample is appropriate because it is representative of the results analysis [25]. Besides, the sampling method we followed in the research is "convenient" or random sampling, in which the researcher selects the closest individuals to serve as respondents and this process continues until the required sample size is obtained [26] [27]. Our sample is considered representative, as we selected the specific individuals for their characteristics, so that we can reach conclusions for the whole. It is also considered appropriate because it is aware of the educational issues we are exploring and voluntarily participates in the study [26] [28].

\section{Issues of Ethics}

The questionnaire used plays an important role in this work. More specifically, there is a reference to ethical issues and the principles of ethics. It should also be 
noted that the participants will be informed that their details and faces will not be disclosed and in this way, their anonymity will be ensured and observed.

Furthermore, some rules must be followed when conducting a survey. More specifically, this research is followed by respect for scientific truth and academic freedom. However, the University of Crete [29] states that in a research there must always be respect for views, beliefs, language, religion and gender. In addition to ethical issues, all specifications must be met so that the results obtained are true and verifiable. It is equally important to note that each person has the right to participate in the research without running any risk and this results in the person feeling safe. However, it is reported that the participant can leave the research at any time he/she wishes, without this meaning that the researcher is greatly affected negatively [29].

In general, it is important to note that every researcher who conducts a survey must be very careful, as the research they conduct is mainly about people. However, pedagogical research cannot be carried out unless the participants are properly and fully informed first about the purposes and reasons for this research and then about the potential risks that may arise. Based on all the above, it has been established that research always requires the consent of the person participating and in this way must be fully informed about the purposes and actions of the research that will be carried out. On the other hand, it should be noted that the consent of the participants cannot always guarantee their protection. Regarding the researcher, when conducting a research, it must be particularly important in terms of the environment and the people to whom it is addressed. For example, there are environments that are not reliable in order to conduct a survey as the opinion of the participants is negatively affected to a large extent [29].

In addition to pedagogical research, there are social ones in which the researcher must first show respect for the cultural and individual differences that arise between the participants. Therefore, we conclude that, when a research is conducted, the researcher must be okay with the participants and fully inform them and in this way is obliged to comply with the codes of ethics and ethics throughout the research [29].

\section{Content Analysis}

As can be seen from the analysis of the questionnaires collected, the results were as follows: Initially, 40 Preschool teachers participated in the present study, of which 26 were women and 6 were men aged 20 to 50 years.

More specifically, the participants had the following years of service. Initially $37 \%$ of participants had 0 - 5 years of service while $15 \%$ had $6-10$ years of service. Another $48 \%$ said they were $15+$ years old. This can be seen in the following pie (Figure 1).

In addition, $72 \%$ of the participants have graduated from universities/technical institutes, while $12 \%$ are IEK graduates, $10 \%$ College graduates, $3 \%$ Assimilation 
and 3\% Postgraduate. This can be seen in the following pie (Figure 2).

In addition to question 3 of the questionnaire, participants answered as follows. More specifically, 7 participants answered that they have some specialization in mathematics, 8 in language, 2 ICT, 5 other subjects and 7 more answered that they specialize in more than one subject. This can be seen in the following pie (Figure 3 ).

Regarding the part of teachers' knowledge in the subject of teaching statistics, $28 \%$ answered "yes" while $72 \%$ answered "no" (Figure 4 ).

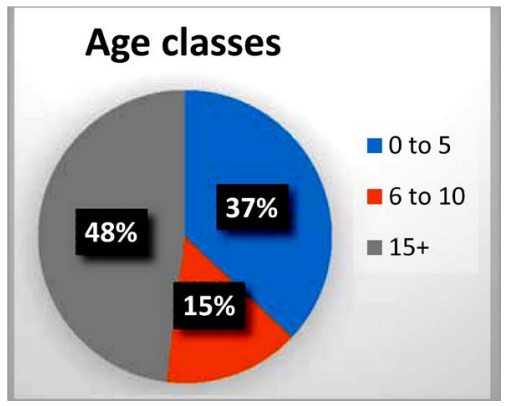

Figure 1. Age classes.

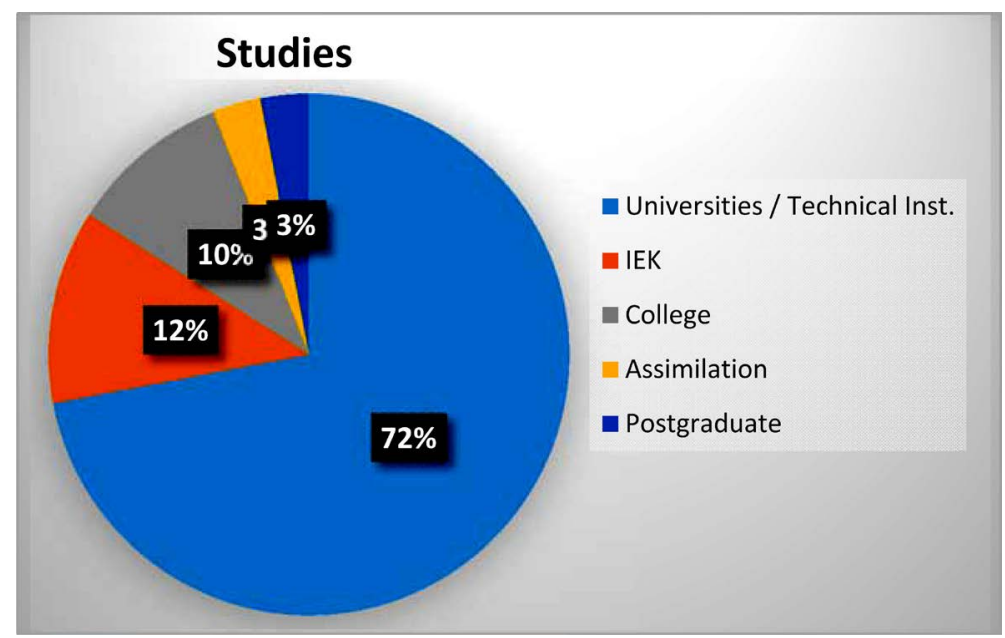

Figure 2. Studies.

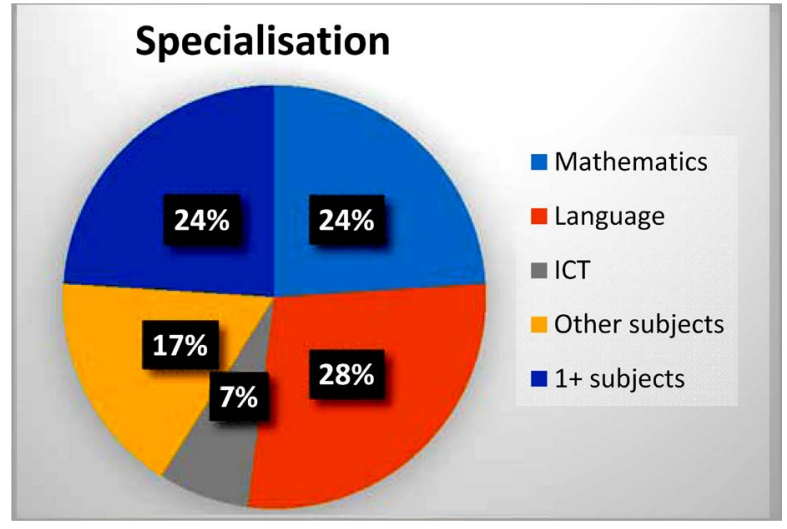

Figure 3. Specialisation. 
In addition to question $4 \mathrm{~b}, 18$ people answered that they had graduated from University, 8 had some knowledge since they were students at school. Another 1 person had obtained knowledge in his Master's degree and 1 more person had acquired knowledge in a Seminar, as you will see in the following pie (Figure 5).

In general, the main purpose of training is on the one hand to train pre-school teachers and on the other hand to improve their views on teaching the subject of statistics. In other words, the training aims to change views and thus expects that the majority of preschool teachers will be able to see in a positive way that teaching the subject of statistics is an interesting part, which concerns the enrichment of mathematics and children's thinking and learning as well. That is, education contributes greatly to creating a common educational level for teachers that is directly related to the subject matter. Moreover, when education aims to improve and develop the services it offers, it is observed that it also takes care of the educational support of teachers. Therefore, in the part of the training contained in the New Curriculum, it was found that $44 \%$ answered no while $56 \%$ answered yes (Figure 6).

In question 6, 12 of the participants answered that they have received knowledge about their training from the Ministry of Education and Culture. 4 more

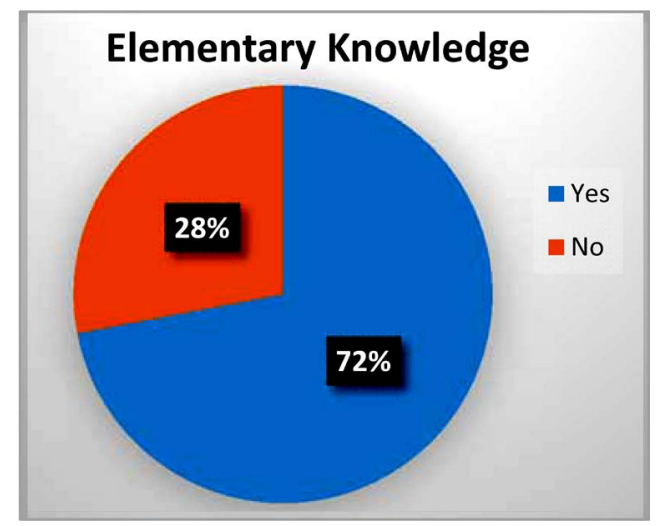

Figure 4. Elementary knowledge.

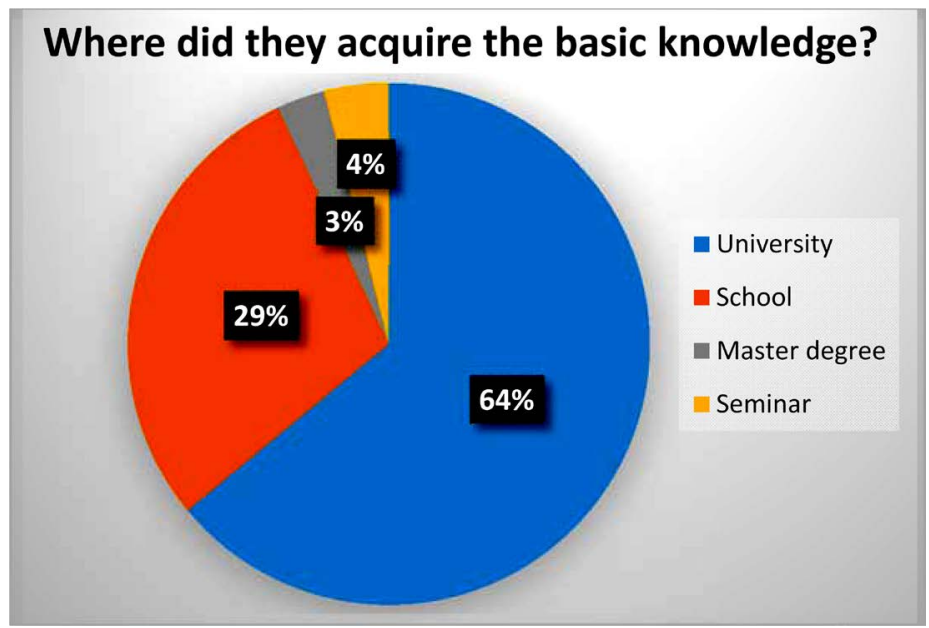

Figure 5. Where did they acquire the basic knowledge? 
participants answered University Foundation and 4 answered Pedagogical Institute while 3 more participants answered Pedagogical Foundation (Figure 7).

More specifically, in question 7, 13 participants answered that they had insufficient knowledge regarding statistics, 4 answered that they have sufficient knowledge. In addition, 3 answered quite adequately, while 18 answered almost adequately. This is also shown in the diagram below (Figure 8).

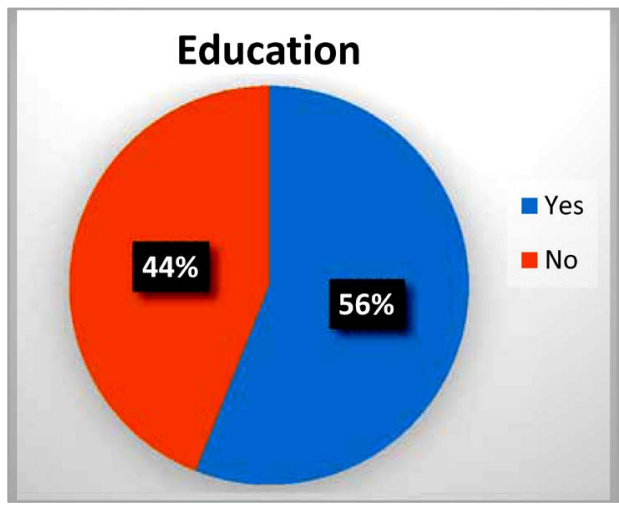

Figure 6. Education.

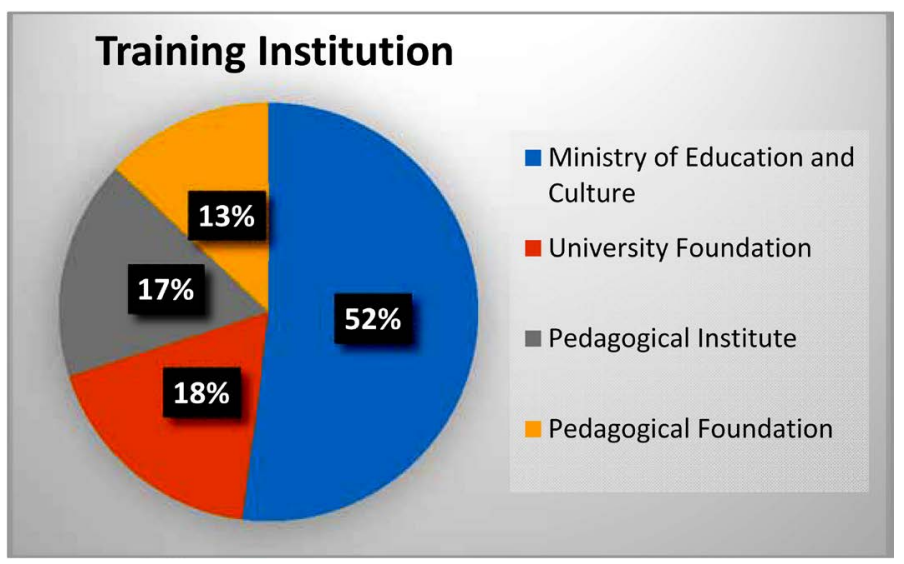

Figure 7. Training Institution.

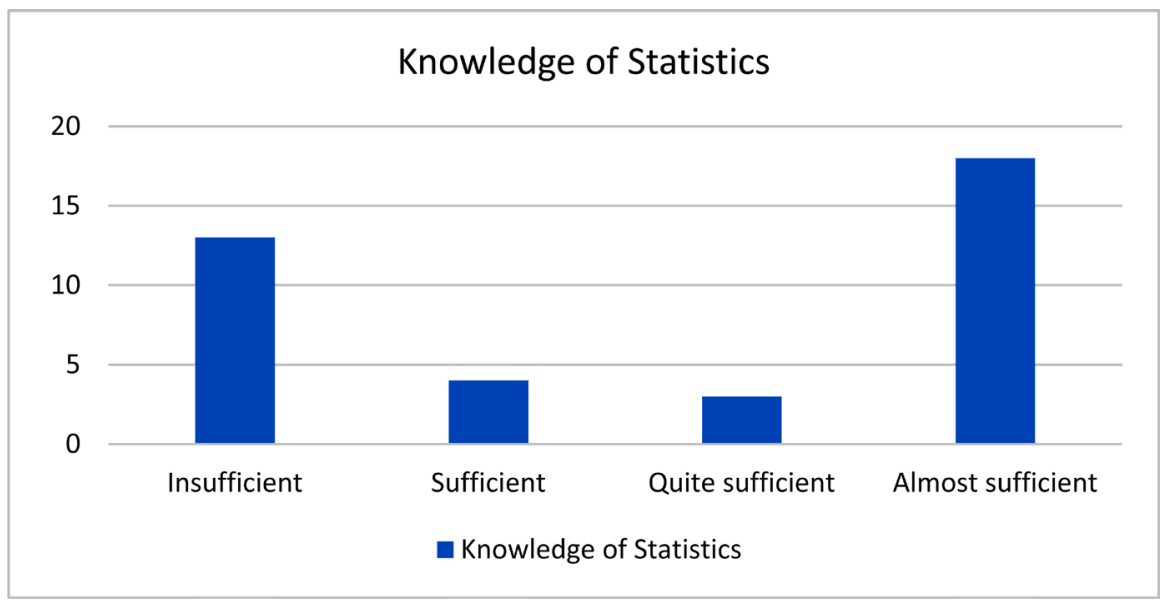

Figure 8. Knowledge of Statistics. 
It is equally important to note that in question 8 some of the participants did not answer as they considered that the subject of teaching statistics in kindergarten is not useful. However, $46 \%$ of the participants answered no while $54 \%$ answered yes (Figure 9).

In particular, in question 9, it was observed that there were many deficiencies in the participants' responses. Of course, 8 people answered that they feel anxious about how to teach children a new concept such as statistics, while 3 of them stated that they feel confident but also insecure. At this point, it should be noted that participants' insecurity is directly related to their fear of being taught concepts such as statistics every time they are asked to teach children, but this insecurity can be set aside when they see that children can to respond positively to the new knowledge of teachers. On the other hand, 5 participants answered that they do not have the appropriate knowledge so that the children learn new things while 3 more answered that they feel strange. In other words, there were few participants who answered that they felt confident as long as they applied simple statistics exercises while the number of other participants stated that it was difficult. Therefore, despite the positive attitude of the participants, it is observed that there is not much confidence in the new subject of teaching statistics, because most of the participants believe that the performance of children, who are usually the driving force, also plays an important role. This is also shown in the diagram below (Figure 10).

In question 10, the percentage of participants answered that $78 \%$ are not able to organize simple activities in the field of statistics while $22 \%$ answered that they are able to organize activities (Figure 11).

Regarding question 11,53\% of the participants answered that the objectives of the New Curriculum can be realized, while $42 \%$ answered that they can be implemented while $5 \%$ answered that it is impossible to implement them (Figure 12).

In addition to question 12, many of the participants answered that in order to be able to achieve the teaching of the subject of statistics, teachers should have the appropriate knowledge so that they can achieve their goals. In other words,

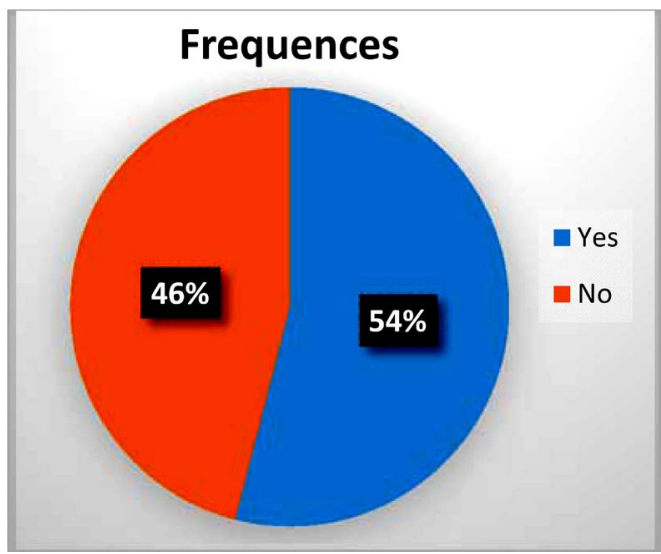

Figure 9. Frequencies. 


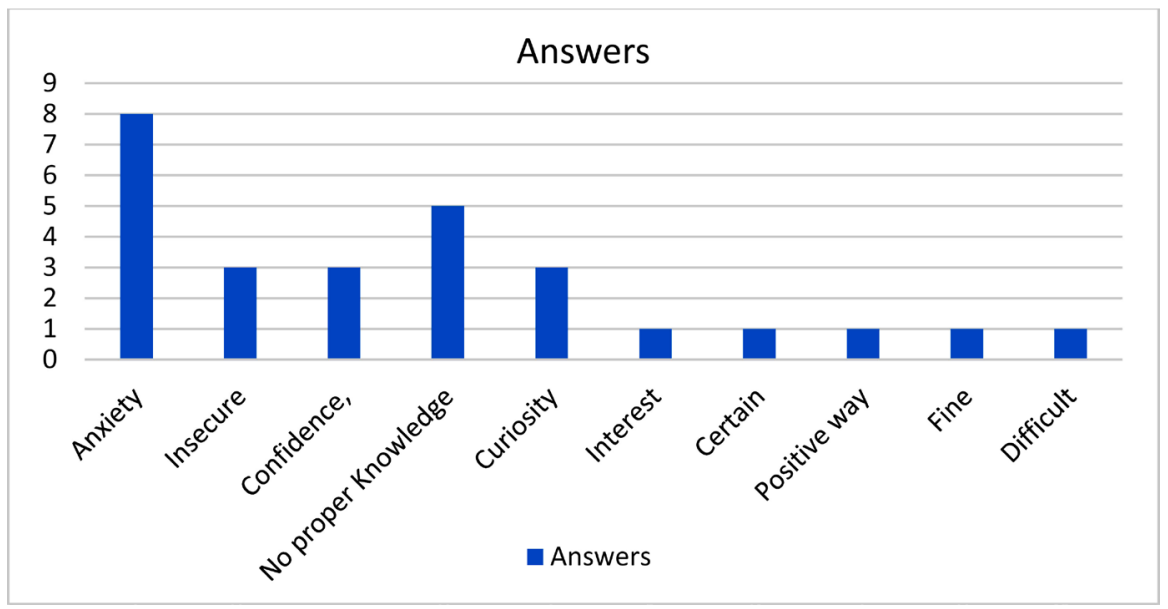

Figure 10. Answers.

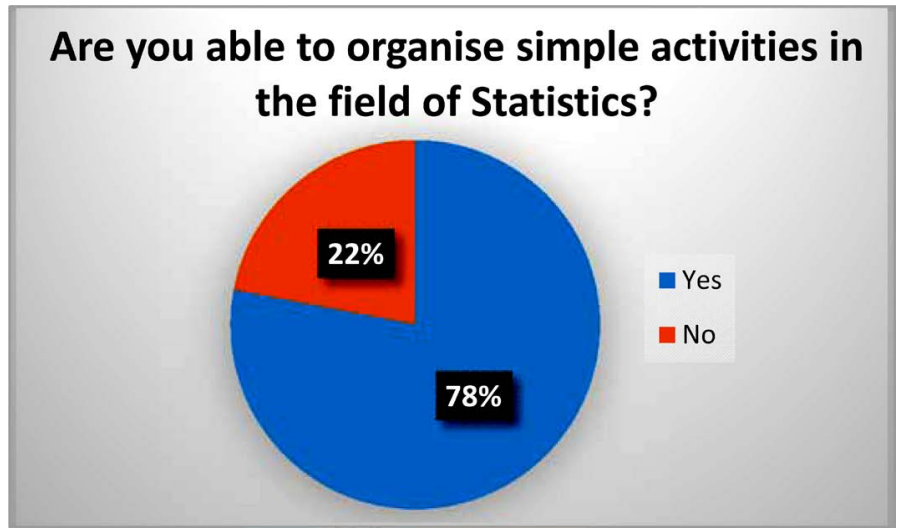

Figure 11. Are you able to organize simple activities in the field of Statistics?

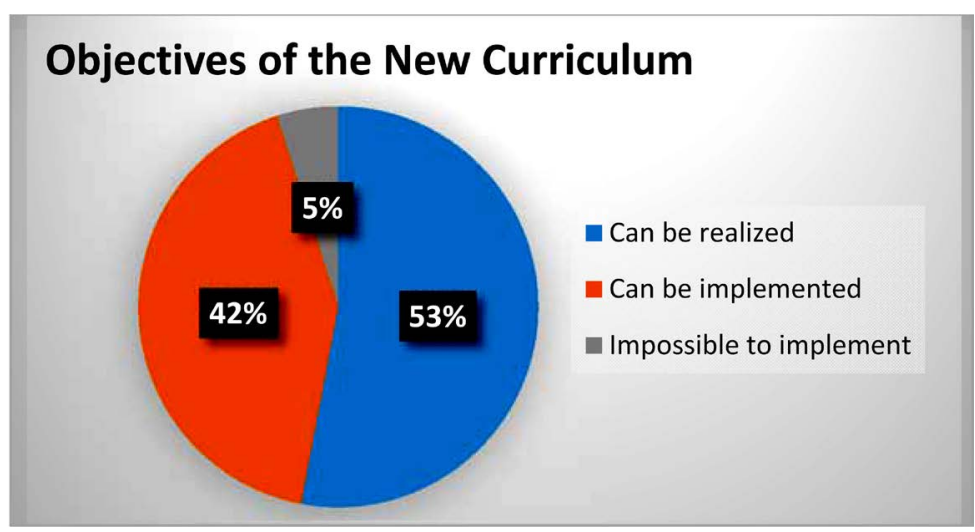

Figure 12. Objectives of the New Curriculum.

they added that educational programs are very useful as teachers gain more knowledge and in this way are able to teach kindergarten children new knowledge such as statistics.

As we will see below, the participants' answers differ greatly as most of them believe that the subject of teaching statistics in kindergarten is difficult to implement. 
In the first diagram (Figure 13) of the first question it is observed that 17 of the participants state that they neither agree nor disagree on whether they are anxious or not about how to teach statistics to kindergarten children. Another 6 of the participants stated that they are absolute when they are stressed by the teaching and another 8 state that they disagree, while 4 do not agree at all and the remaining 5 agree completely.

In contrast to the second diagram (Figure 14) in question two, it has been found that the largest number of participants reaches 15 people, who state that they neither agree nor disagree. In addition, there is a small difference between the number of participants who disagree, which is 12 , while a smaller number has been observed in those who answered that they completely disagree 3 , and in those who fully agree 2 .

However, in the third diagram (Figure 15) it is observed that there is another small difference in the participants' answers. In other words, as we will see in the table below, 13 people stated that they neither agree nor disagree, while 14 stated that they disagree. However, 4 stated that they completely disagree as they do

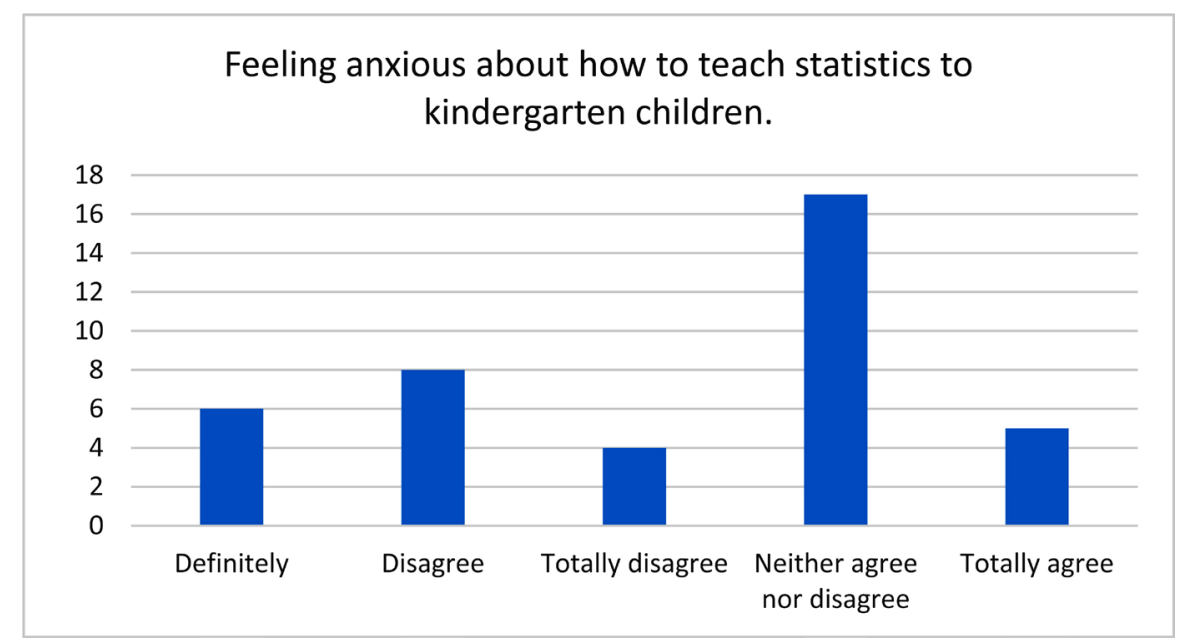

Figure 13. Feeling anxious about how to teach statistics to kindergarten children.

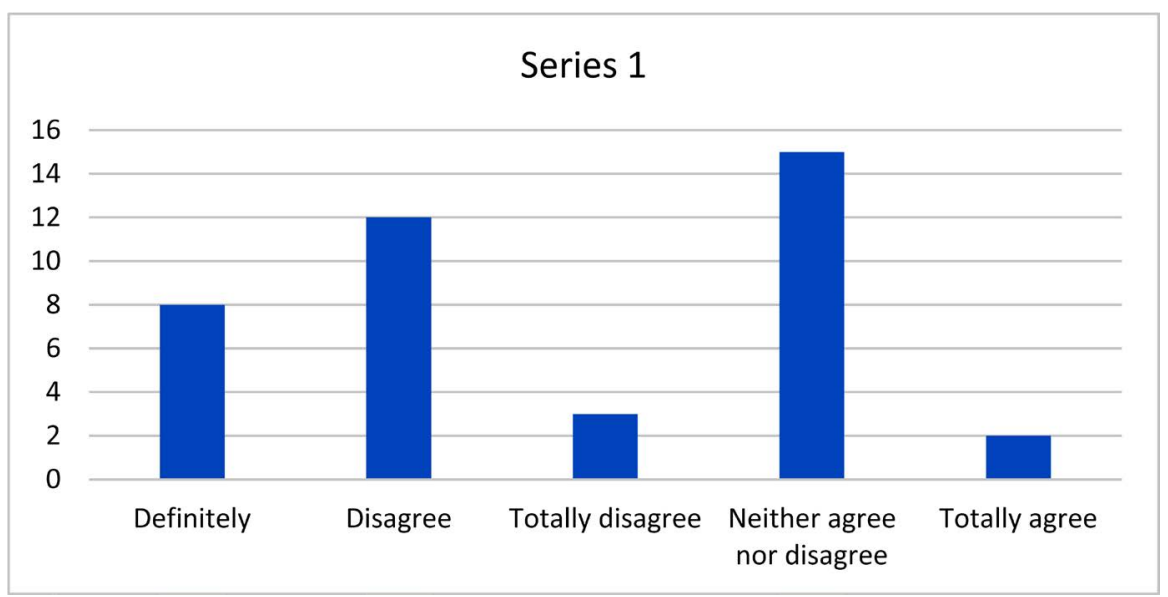

Figure 14. Series 1. 
not feel confident when answering questions that have to do with statistical concepts. Finally, 6 participants stated completely while 3 others stated that they completely agree when asked if they are confident enough to meet the statistics requirements.

In addition to question 4 , there is again a small difference between the participants' answers as 14 stated that they neither agree nor disagree so that they can develop statistical activities while 12 stated absolutely (Figure 16). It should also be noted that 8 of the participants disagreed as they find it difficult to solve the children's questions about statistical activities while 4 completely disagreed and 2 more completely agreed, because they believe that with statistical activities children will develop more their mathematical thinking.

Regarding the question five from the table of the questionnaire, it is observed that 17 participants answered that they neither agree nor disagree that they can incorporate statistical activities and 7 people disagree (Figure 17). However, the same number of participants answered completely, i.e. they can implement statistical activities in the kindergarten. Finally, there is another difference with one point as 4 of the participants answered that they completely agree while 5 disagree completely.

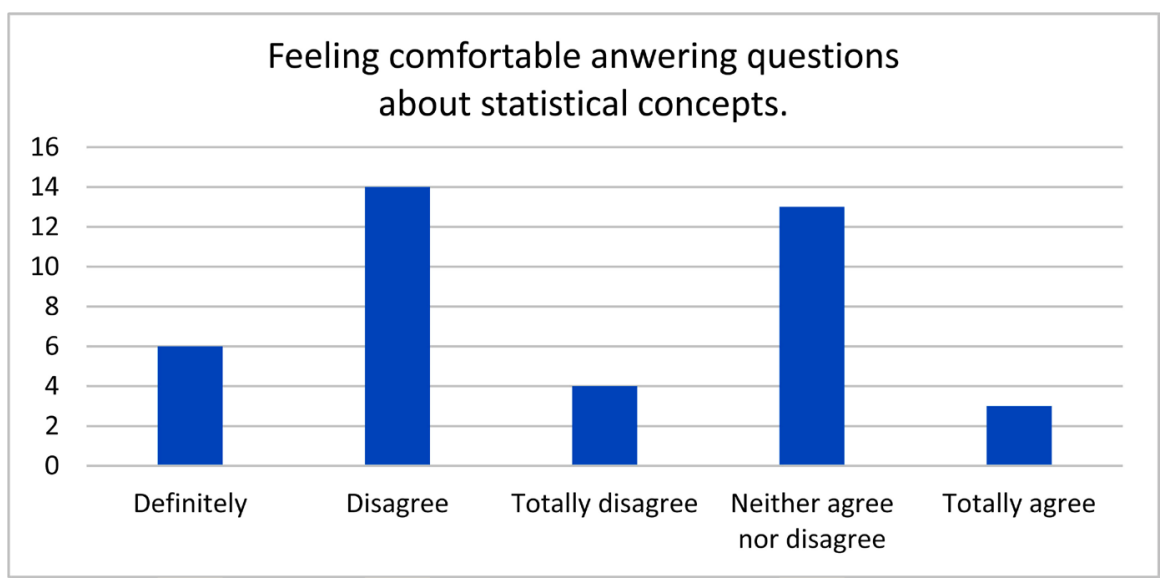

Figure 15. Feeling comfortable answering questions about statistics concepts.

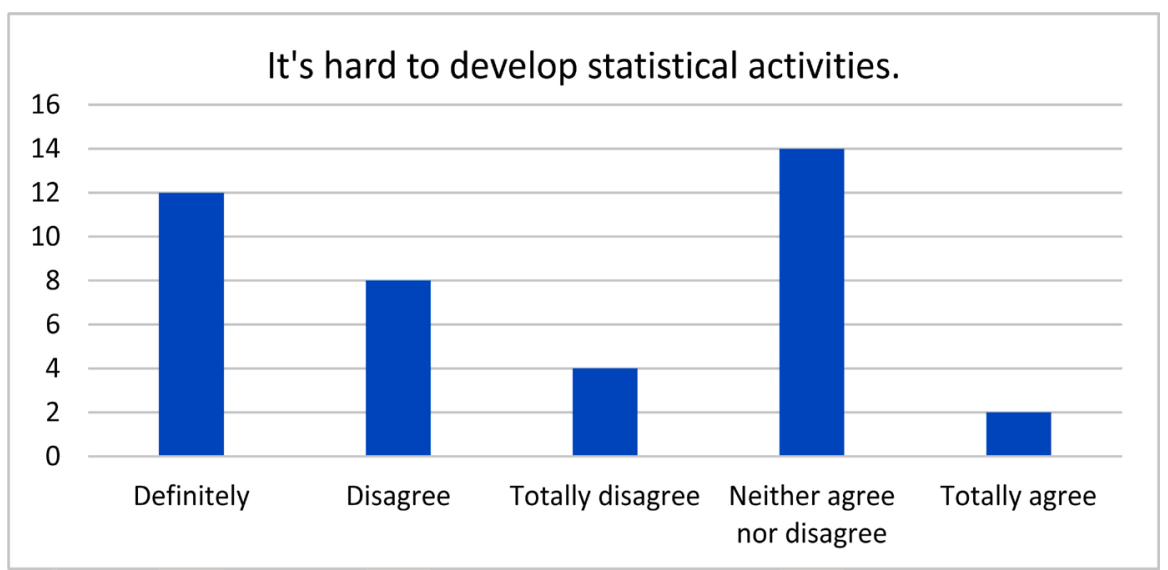

Figure 16. It's hard to develop statistical activities. 
In addition to the question six, 14 participants answered that they neither agree nor disagree with adapting the teaching of the subject of statistics, so that the subject of mathematics becomes more interesting. In fact, 8 of the participants stated that they can fully adapt the teaching of statistics while 7 answered that they disagree (Figure 18). Finally, 9 answered completely disagree and 1 participant replied that he completely agrees.

In question seven, it was observed that 18 participants answered that they neither agreed nor disagreed that the statistics might be interesting for kindergarten children. In addition, 7 responded completely while 9 disagreed as they believe that the statistics are difficult for the kindergarten. Also, 4 answered that they completely disagree, while 2 answered that they completely agree because they believe that teaching statistics is an interesting part of children's learning (Figure 19).

In addition, in question 8 there is a difference between the participants' answers as 13 answered that they are absolute in that the statistics generally offer the development of children's mathematical thinking while 10 answered that they neither agree nor disagree. However, 8 answered that they disagree and 3

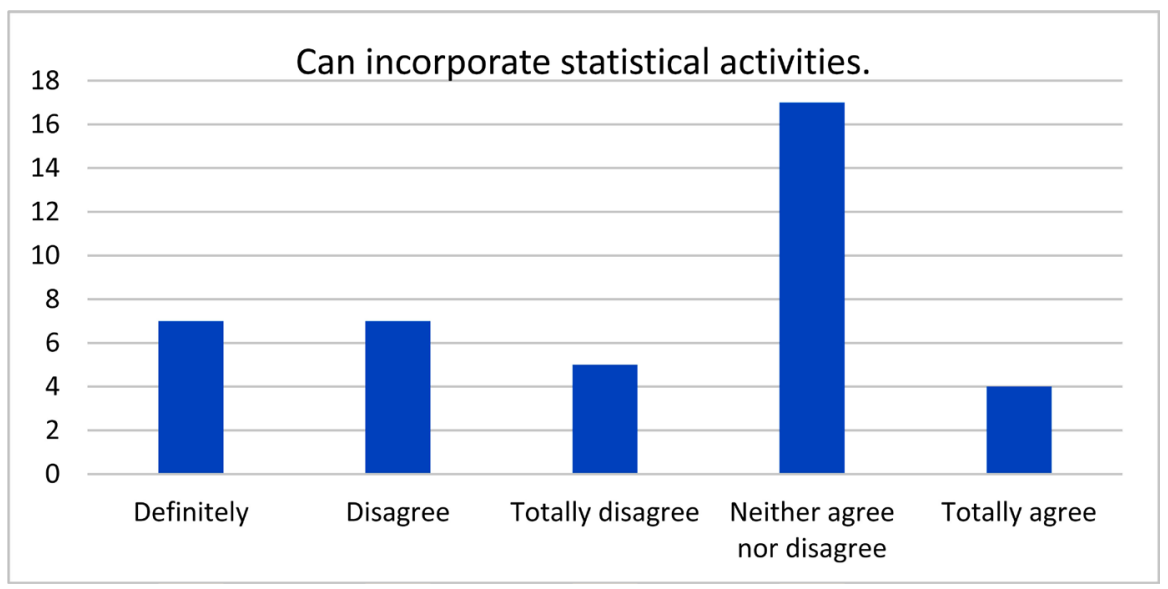

Figure 17. Can incorporate statistical activities.

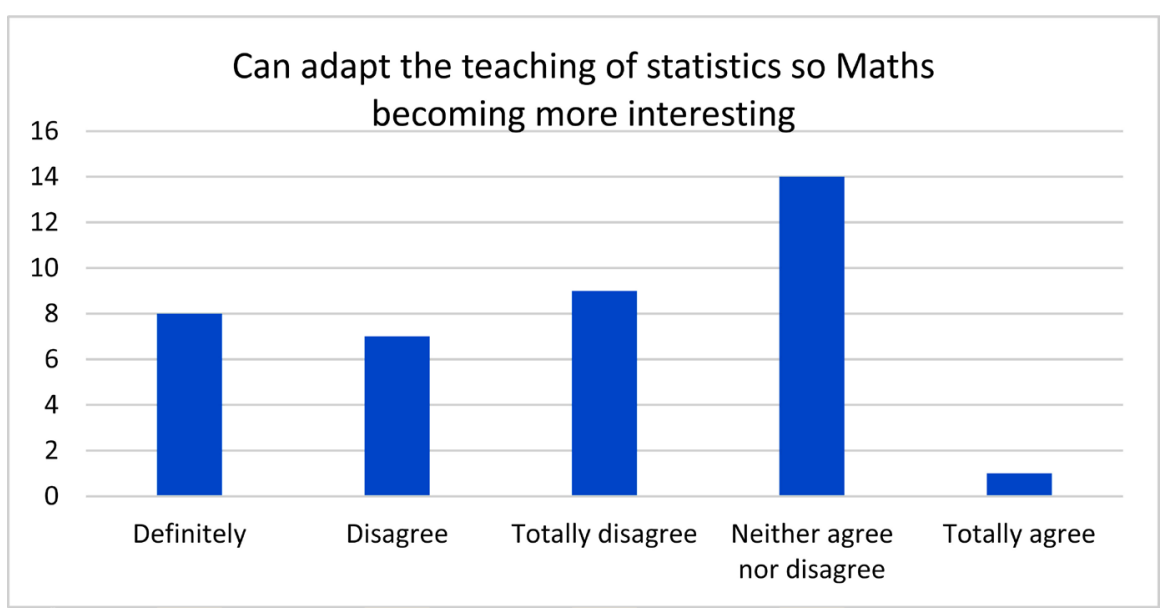

Figure 18. Can adapt the teaching of statistics so Maths becoming more interesting. 


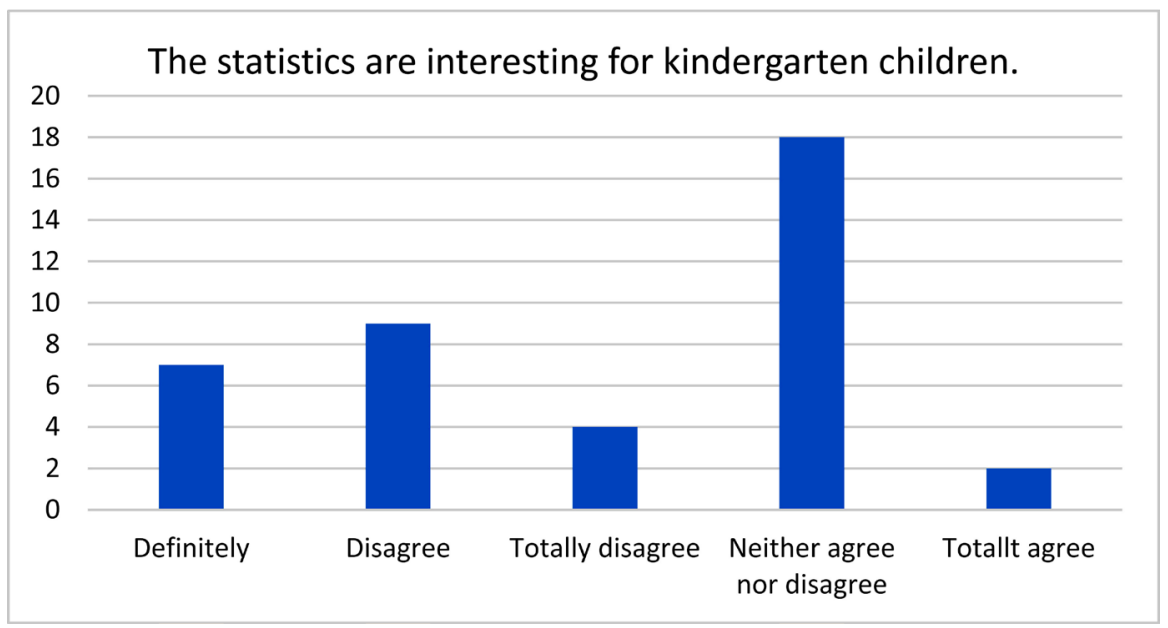

Figure 19. The statistics are interesting for kindergarten children.

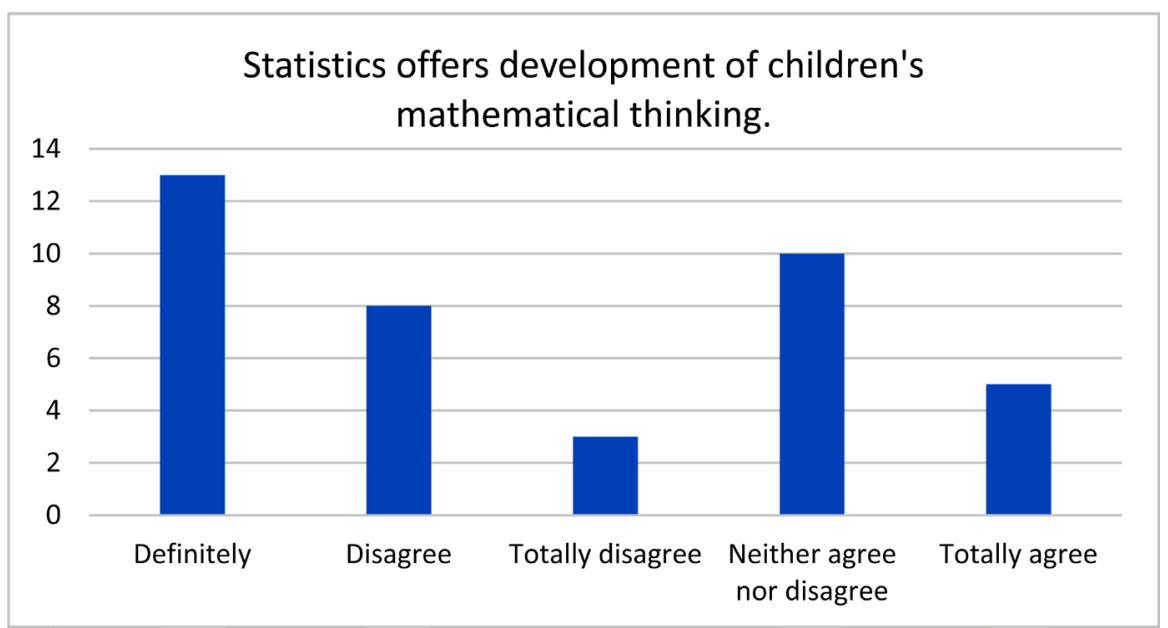

Figure 20. Statistics offers development of children's mathematical thinking

answered that they completely disagree because they believe that the statistics will confuse the children. Finally, 5 answered that they completely agree. This is also shown in the diagram below (Figure 20).

More specifically, question 9 shows that 14 participants answered perfectly while 5 disagreed as they believe that the development of statistics in kindergarten is an excessive goal. However, 4 answered that they completely disagree, while 13 neither disagree nor agree. Finally, 4 answered that they completely agree (Figure 21).

Regarding question 10, the largest number of participants, ie 17 of the participants, answered that they neither agree nor disagree, while 7 answered completely. Another 8 answered that they disagree and 4 completely disagree. Finally, 4 answered that they completely agree. This is also shown in the diagram below (Figure 22).

In particular, in question 11, 10 of the participants answered that they neither agree nor disagree with the development of a variety of activities in the field of statistics in kindergartens. Then 5 of the participants answered that they completely 
disagree while a small difference is observed in those who answered that they disagree, the number of participants who stated that they disagree is 4 . Finally, 12 participants answered completely while 8 answered that they completely agree. This is also shown in the diagram below (Figure 23).

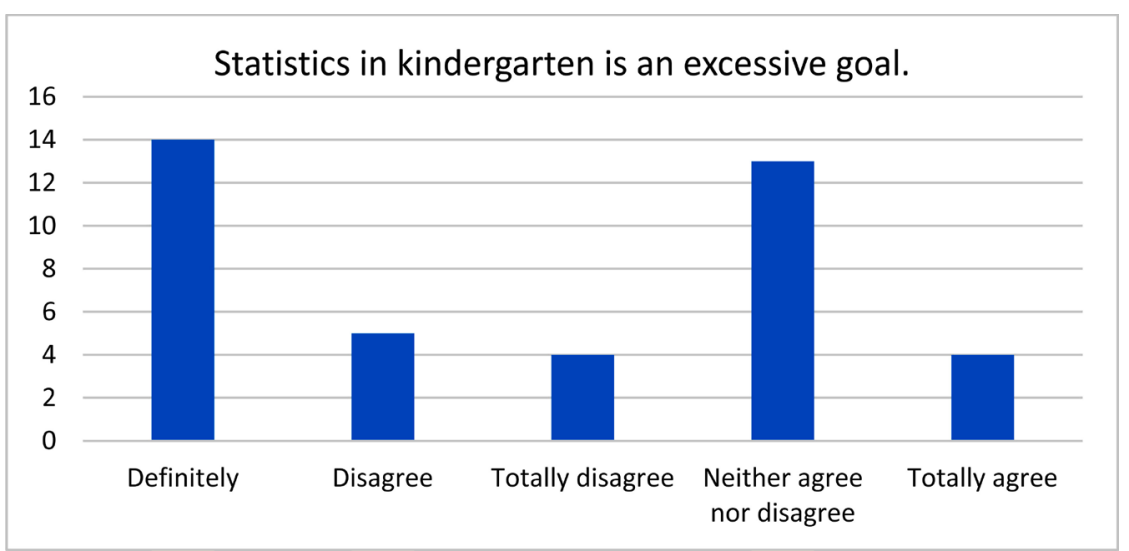

Figure 21. Statistics in kindergarten is an excessive goal.

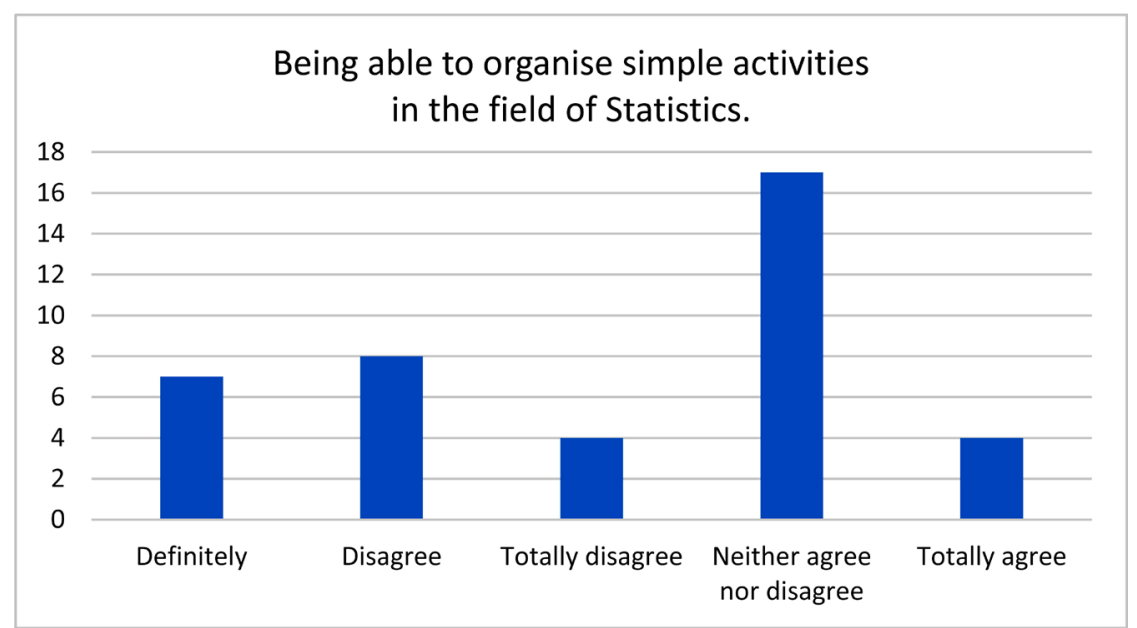

Figure 22. Being able to organise simple activities in the field of Statistics.

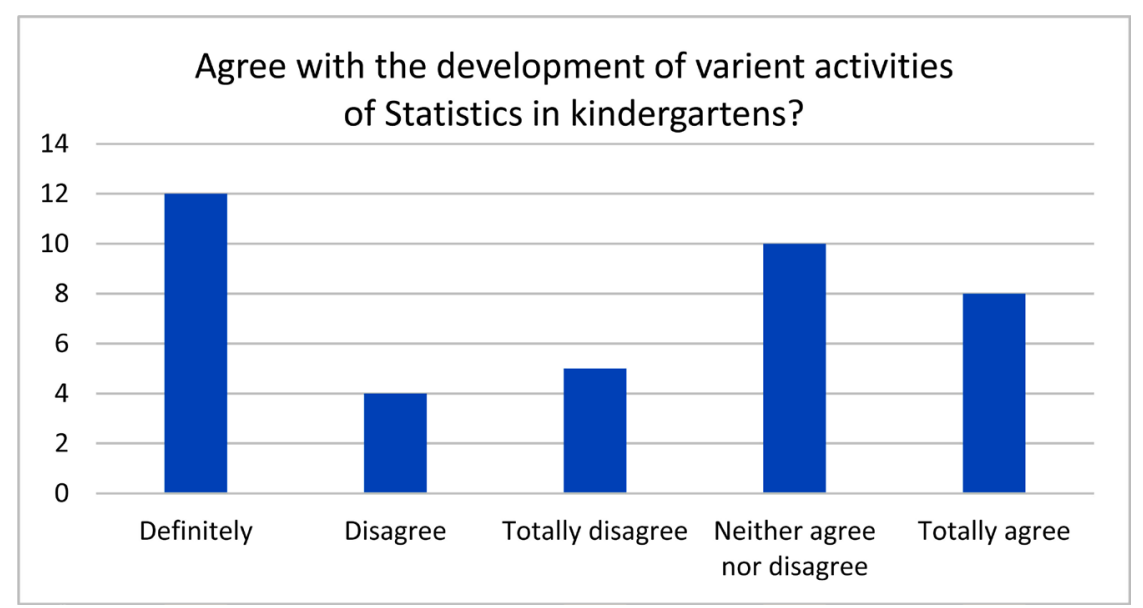

Figure 23. Agree with the development of varient activities of Statistics in Kindergartens. 


\section{Adding Knowledge to Pre-Existing One}

From the research of the studies and the bibliographic review that was done in the present work, it was observed that there are a large number of researches that have studied the teaching of the subject of statistics in kindergarten. In particular, this research is particularly useful because it concerns the value of recording teachers' attitudes and views, as they refer to identifying the problems that teachers today face in general and special education at all levels of education [30]. However, it is equally important to mention that in the future, it would be interesting to have a larger sample of educators conducting a survey, which will come from all the geographical areas of Greece. In other words, such research would be able to produce results that could be generalized.

\section{Conclusions}

As it turned out from all that was found in the following research, it was found that the results were largely remarkable. More specifically, the training of preschool teachers had a positive effect on the one hand, in terms of their views on the teaching of the subject of statistics in kindergarten, but on the other hand, negative views were created on whether pre-school teachers are able to teach statistics in kindergarten [31].

In addition, teachers today are a peculiar group of apprentices. In other words, their daily effort contributes greatly as it is not always easy to respond honestly to points that challenge their professional prestige. However, this study has yielded some interesting findings regarding teachers' views on teaching the subject of statistics in kindergarten. However, it is equally important to note that the views of preschool teachers differ greatly in whether each of them is able to cope with an activity that will affect their receptivity to new knowledge and this will be able to enhance his/her self-confidence so that he/she can promote a positive result for the teaching of the subject of statistics, as well as his/her perception of the usefulness of the subject [32] [33]. Therefore, the conclusions that have emerged are not generalizable propositions but highlight important aspects of pre-school teachers' views on whether statistics in kindergarten are particularly useful and necessary in children's mathematical education [34].

\section{Suggestions and Restrictions}

In the present study, an attempt was made through the appropriate research tool-questionnaire, data collection by preschool educators and statistical analyzes to investigate and answer research questions related to the way in which Statistics can be taught in Kindergarten.

However, as mentioned above, what bothered me about conducting this research was the small sample of teachers I managed to collect, that is, my sample was 40 teachers and I had a hard time collecting these questionnaires because the research was conducted at first place a few days before the Christmas period, so when the they came back I had a hard time to recollect all the data needed. 
However, the positive thing about this situation is that the answers given by these people and through their honesty helped me to produce well-documented results.

Another limitation was that the questionnaire was self-reporting, meaning that deviations from the actual mood and attitude of teachers that may be due to the conscious or unconscious intention of participants not to express their image with true beliefs could not be avoided regarding to their answers. Of course, the tool was valid and reliable and the participation was voluntary.

Another limitation of this research was the total number of volunteers in research, i.e. the inability to compare the general characteristics of the participants with those who did not participate, this is due to the inability to assess personal data and beliefs with the decision to participate in the research.

\section{Future Research}

What is desirable in future research is the introduction of other exploratory factors and correlations, such as stress, ambiguity and role conflict, according to the dimensions of teaching the subject of statistics in kindergarten, occupational safety based on weakening, so as to use the qualitative data collection method, which aims to make a more complete record of the attitudes and beliefs that teachers have today to teach the subject of statistics in kindergartens.

\section{Acknowledgements}

This study would not have been possible without the contribution of numerous people. We would like to thank each and every one of the educational staff who took part in the research.

\section{Conflicts of Interest}

The author declares no conflicts of interest regarding the publication of this paper.

\section{References}

[1] Nikiforidou, Z. and Pagge (2012) Statistical Literacy in Kindergarten. Proceedings of the Hellenic Institute, Applied Pedagogy and Education, 5-7 October 2012.

[2] Broers, N.J. (2006) Learning Goals. The Primacy of Statistical Knowledge. Proceedings of the Seventh International Conference on Teaching Statistics Institute and International Association for Statistical Education.

[3] Ministry of Education (1997) Unified Mathematics Curriculum Framework. In: Von Glaserferd, E., Ed., Radical Constructivism in Mathematics Education.

[4] Koleza, E. (1997) The Role of Activities in the Teaching of Mathematics. Proceedings of the 14th Panhellenic Conference of the Hellenic Mathematical Society, Mytilene.

[5] Killpatrick, J., Swafford, I. and Findell, B. (2001) Adding It Up: Helping Children Learn Mathematics. National Academy Press, Washington DC.

[6] Batanero, C., Burrill, G. and Readin, C. (2011) Overview: Challenges for Teaching 
Statistics in School Mathematics and Preparing Mathematics Teachers. In: Carmen Baterano, G.B., Ed., Teaching Statistics in School Mathematics-Challenges for Teaching and Teacher Education: A Joint ICMII IASE Study. The 18th ICMI Study, Springer, Heidelberg, 407-418. https://doi.org/10.1007/978-94-007-1131-0

[7] Kontogianni, A. (2014) The Statistical Literacy in the Curriculum of Mathematics of the Primary School. Doctoral Thesis, University of Patras, Patras.

[8] Chatzipantelis, Th. (2003) The Child's Path in Statistics and the Possibilities from Preschool to Adulthood. In: 20th Panhellenic Conference on Mathematical Education, EME, Veria.

[9] Copley, J.V. (2004) The Early Childhood Collaborative: A Professional Development Model to Communicate and Implement. In: Samara, D.H., Ed., Enanging Young Children in Mathematics, Standards for Early Childhood Mathematics Education, Lawrence Erlbaim Associates, London.

[10] Kaffousi, S. (2006) Reading Visual Representations of Data with Kindergarten Children. International Group for the Psychology of Mathematics Education, 266.

[11] Pedagogical Institute (2011) Mathematics in Primary Education (Primary). Guide for the Educational “Teaching Approaches Tools”. http://ebooks.edu.gr/new/ps.php

[12] Pedagogical Institute (2011) Curriculum for Mathematics in Compulsory Education. http://ebooks.edu.gr/new/ps.php

[13] Skoubourdi, X. and Kalavasis, F. (2009) The Role of Play in Mathematical Education, Pedagogical Review.

[14] Gal, I. (2004) Statistical, Literacy Meanings, Components, Responsibilities. In: Benzi and Garfied, J., Eds., The Challenge of Developing Statistical Literacy, Reasoning and Thinking, Kluwer Academic Publishers, Dordrecht, 47-78. https://doi.org/10.1007/1-4020-2278-6 3

[15] Jones, G., Langrall, C. and Mooney, E. (2007) Research in Probability Responding to Classroom Realities. In: Lester, F., Ed., Second Handbook of Research on Mathematics Teaching and Learning, Macmillan, New York.

[16] Franklin, C., Kader, G., Mewborn, D., et al. (2005) Guidelines for Assessment and Instruction in Statistics Education. (GAISE) Report: A pre-k-12 Curriculum Framework. American Statistical Association, Alexandria.

[17] Cohen, L., Manion, L. and Morison, K. (2008) Educational Research Methodology. Athens Publications, Metaichmio.

[18] Athanasiou, L. (2007) Research Methods and Techniques in Educational Sciences. Athens, Publications, Efyra.

[19] Paraskevopoulos, I. (1993) Scientific Research Methodology. First Volume.

[20] Paraskevopoulos, I. (1999) Interpersonal and Intrapersonal Adaptation Questionnaire. Ellinika Grammata, Athens.

[21] Aggelopoulou, D. (2015) The Contribution of the Education in the Modification of the Perceptions of the Kindergarten Teachers for Their Didactic Self-Sufficiency in the Teaching of the Subject of the Probabilities in the Preschool Education.

[22] Kyriazopoulos, P. and Samanta, E. (2011) Research Methodology, Elaboration of Diploma Theses.

[23] Argyriou, G. and Kassou, B. (2014) Theoretical Analysis in Research Types: Quantitative and Qualitative: Business Research Methods: Quantitative and Qualitative Approach.

http://okeanis.lib2.uniwa.gr/xmlui/bistream/handle/123456789/2585/de 201400225 
.pdf? sequence $=1$ andisAllowed $=y$

[24] Anastasiadou, S.D. (2012) Statistics and Research Methodology in the Social Sciences. Athens, Publications, Kritiki.

[25] Morrison, K.R.B. (1993) Planning and Accomplishing School-Centred Evaluation. Peter Francis Publishers, Norfolk.

[26] Creswell, J. (2016) Research in Education: Design, Conduct and Evaluation of Quantitative and Qualitative Research (Translated by N. Kouvarakou). Ion, Athens. (Year of Publication of the Original 2005)

[27] Cohen, L., Manion, L. and Morrison, K. (2008) Educational Research Methodology. Metaichmio, Athens.

[28] Robson, C. (2010) Real-World Research-A Tool for Social Scientists and Professional Researchers (Translated by V. Dalakou, K. Vasilikou). Gutenberg, Athens. (1993 Edition)

[29] University of Crete (2012) Research Ethics Code.

[30] Charitaki, G., Tzivinikou, S., Stefanou, G. and Soulis, S.G. (2020) A Meta-Analytic Synthesis of Early Numeracy Interventions for Low-Performing Young Children.

[31] Charitaki, G., Baralis, G., Polychronopoulou, S., Lappas, D. and Soulis, S.G. (2014) Factors Related to Numerical Ability of Children with Down's Syndrome. The International Journal of Early Childhood Learning, 21, 1-17. https://doi.org/10.18848/2327-7939/CGP/v21i01/48429

[32] Charitaki, G., Baralis, G., Polychronopoulou, S., Lappas, D. and Soulis, G.S. (2015) Difficulty in Learning to Count or Effect of Short-Term Memory Deficiency in Mathematical Abilities. International Journal of Innovation and Research in Educational Sciences, 2, 60-62.

[33] Charitaki, G., Baralis, G., Polychronopoulou, S., Lappas, D. and Soulis, G.S. (2014) Early Numeracy in Children with Down's Syndrome in Greece. Psychology, 5, 1426-1432. https://doi.org/10.4236/psych.2014.512153

[34] Sarikaya, İ., Töman, U. and Öztürk, M. (2018) Examining the Variables Predicting Attitudes towards Teaching Profession of Preservice Classroom Teachers. Acta Didactica Napocensia, 11, 129-141. https://doi.org/10.24193/adn.11.1.10 